\title{
Disciplinas de Geociências do Bacharelado em Engenharia de Petróleo da Universidade de São Paulo e a proposta curricular da Society of Petroleum Engineers
}

\author{
Geosciences disciplines in the Petroleum Engineering degree of Sao Paulo University and the curricular proposal of \\ Society of Petroleum Engineers
}

Augusto Gonçalves Nobre, Pedro Amoroso de Andrade, Odila Florêncio

Departamento de Geologia Sedimentar e Ambiental. Instituto de Geociências. Universidade de São Paulo.

E-MALl: AUGUST0.GONCALVES@USP.BR,.PEDRO.AMOROSO.ANDRADE@USP.BR, 0DILA.FLORENCIO@MACKENZIE.BR

\begin{abstract}
The University of Sao Paulo's Bachelor's Degree in Petroleum Engineering was created in 2002 to meet the demand for specialized working force in the oil industry. The program has a significant load of disciplines consisting of mandatory classes on Geosciences. The Society of Petroleum Engineers (SPE), in an effort to maintain good technical formation of professionals, has created a curricular proposal for Bachelor's programs in 2014. The present paper seeks to present the Geosciences disciplines in the University's program and compare them with the Society of Petroleum Engineers' curricular proposal, analyzing the way in which the University is now seeking to meet the demands of technical formation in Geosciences that the professional market presents. This work found that the University of Sao Paulo offers a wide range of theoretical disciplines, while the SPE has a much more practical view on the subjects that those programs should address.
\end{abstract}

Resumo: 0 Bacharelado em Engenharia de Petróleo da Universidade de São Paulo foi criado em 2002 para atender a demanda por mão-de-obra especializada para a indústria petrolífera. 0 curso possui uma carga horária significativa dedicada às disciplinas obrigatórias de Geociências. A Society of Petroleum Engineers (SPE) em seu engajamento pela manutenção da boa formação de profissionais criou uma proposta curricular para os cursos de Bacharelado no ano de 2014. Este trabalho teve como objetivo apresentar as disciplinas de Geociências presentes no curso da Universidade e compará-las com a proposta curricular da SPE, analisando como a Universidade está se propondo a atender as demandas de formação geocientífica dos profissionais solicitadas pelo mercado. № trabalho foi possível concluir que a Universidade oferta um leque de disciplinas teórico-acadêmicas muito significativo, ao passo que a SPE possui visão mais prática sobre o que 0 curso deve abordar.
Citation/Citação: Nobre, A. G., Andrade, P. A., \& Florêncio, 0. (2020). Disciplinas de Geociências do Bacharelado em Engenharia de Petróleo da Universidade de São Paulo comparadas com a proposta curricular da Society of Petroleum Engineers. Terræ Didatica, 16, 1-11, e020020. doi:10.20396/td.v16i0.8657989.

Keywords: Engineering Education. Petroleum Engineering. Geosciences Education.

Palavras-chave: Ensino da Engenharia. Engenharia de Petróleo. Ensino de Geociências.

Manuscript/Manuscrito:

Received/Recebido: 20/01/2020

Revised/Corrigido: 24/03/2020

Accepted/Aceito: 05/05/2020

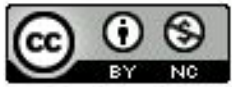

\section{Introdução}

O curso de Bacharelado em Engenharia de Petróleo da Universidade de São Paulo (USP), criado em 2002, possui um significativo elenco de disciplinas obrigatórias de Geociências em sua grade. Apesar de evidentemente fundamentais para a formação do engenheiro de petróleo, as ementas das disciplinas não devem ser sobrepostas, tampouco genéricas (ou mesmo aprofundadas) demais para o estudante, além de estar alinhadas com as demandas modernas do mercado de trabalho. Por esse motivo, o trabalho se dispõe a analisar o conteúdo programático das disciplinas de Geociências do curso mencionado, comparando-o com a "Proposta Curricular para os Cursos de Bacharelado em Engenharia de Petróleo" elaborada pela Society of Petroleum Engineers (SPE, 2014). O objetivo é fomentar a discussão a respeito da grade de disciplinas do curso de Bacharelado em Engenharia de Petróleo da Universidade, visando verificar se atendem às demandas do mercado e à legislação que regulamenta a profissão no Brasil. 
O trabalho apresentará um breve panorama histórico da criação dos cursos de Engenharia do Petróleo no Brasil, a fim de esclarecer a motivação por trás da busca de profissionais especializados na área. Terá destaque a apresentação do curso da Escola Politécnica da USP (Poli-USP), objeto de estudo deste trabalho.

Após contextualizar o crescimento pela demanda por mão-de-obra nacional especializada para a indústria petrolífera, o trabalho se voltará à apresentação da evolução programática do curso da Poli-USP, ainda visando à compreensão da história recente da formação de engenheiros do petróleo pela USP. O tópico servirá de ligação entre as considerações históricas e a análise pretendida neste artigo propriamente dita.

A análise apresentada se baseou em dados e estatísticas a respeito das matérias de Geociências com relação ao total do curso de Engenharia de Petróleo. As disciplinas em si também serão descritas, o que permitirá o levantamento de quadro comparativo com a proposta da Society of Petroleum Engineers (SPE, 2014) e a verificação de divergências entre as propostas didático-pedagógicas. É importante frisar que não há pretensão em se distinguir qualitativamente as propostas curriculares. Entende-se que ambas as visões são importantes e refletem o resultado dos esforços coletivos de seus formuladores, influenciados pelas suas práticas e experiências no exercício profissional.

Ao final do trabalho, é apresentada uma sugestão de reforma curricular cujo propósito é orientar a discussão a respeito de uma possível atualização da grade curricular para as disciplinas de Geociências na Universidade.

Este artigo, de forma alguma, propõe-se a ser determinístico e absoluto em suas considerações, mas objetiva abrir a discussão e fomentar possível evolução da grade curricular com sugestões de mudanças de ementas e disciplinas.

\section{Panorama histórico da Engenharia de Petróleo no Brasil e na USP}

Na década de 1990, a Petróleo Brasileiro S. A. (Petrobras) alcançou marca inédita de exploração de óleo e gás offshore em profundidade, atingindo 1800 metros de lâmina d'água em 1999 (Ortiz Neto \& Costa, 2007). Foi justamente nesse período (mais precisamente, no ano de 1994) que surgiu o primeiro curso de Bacharelado em Engenharia de
Petróleo no Brasil, na Universidade Estadual do Norte Fluminense (UENF). O curso de graduação somou-se a cursos de pós-graduação pré-existentes na área, como o Programa de Pós-Graduação em Engenharia de Petróleo da Universidade Estadual de Campinas (Unicamp), criado em 1987.

A ascensão da indústria petrolífera brasileira esteve diretamente ligada à difusão do ensino superior voltado à área. Além do incentivo criado pela exploração offshore na década de 1990, um novo pulso de criação de cursos de bacharelado surgiu a partir de, 2006, ano em que surgiram os primeiros indícios dos vastos depósitos de hidrocarbonetos do Pré-Sal. Neste novo contexto, diversas instituições de ensino superior fundaram cursos de Bacharelado em Engenharia de Petróleo, chegando a mais de 35 oferecimentos em território brasileiro no ano de 2012.

Este trabalho analisa especificamente o caso da USP, cujo curso de Engenharia de Petróleo é oferecido pela Poli-USP desde 2002. A criação do curso, à época, esteve relacionada a mudanças na conjuntura técnica e econômica da indústria nacional, como o fim do monopólio estatal de exploração do petróleo enunciado pela Lei n. 9.478/1997 (Brasil, 1997), o que passou a atrair empresas estrangeiras a se estabelecerem no Brasil; à criação da Agência Nacional do Petróleo, Gás Natural e Biocombustíveis (ANP), em 1997; e à crescente necessidade de mão de obra especializada na área.

Inicialmente, o curso possuía dez vagas anuais. Seu oferecimento, durante os dez primeiros anos de existência, deu-se no campus da Cidade Universitária Armando Sales de Oliveira, no município de São Paulo, estado de São Paulo, vinculado ao Departamento de Minas e de Petróleo (PMI) da Universidade.

Em 2012, o curso foi transferido para a cidade de Santos, inaugurando um campus da USP pela primeira vez no litoral do estado de São Paulo e, ao mesmo tempo, proporcionando ao curso de Engenharia de Petróleo uma aproximação com seu potencial mercado regional, que se pensava à época ser bastante promissor. O curso de bacharelado manteve-se com dez vagas em seu primeiro ano no município de Santos e passou a ter 50 vagas anuais a partir de 2013, quantidade que se manteve até hoje. O curso está sediado no Edifício Cesário Bastos, prédio histórico da cidade de Santos fundado em 1916, tombado pelo Conselho de Defesa do Patrimônio Histórico, Arqueológico, Artístico e Turístico (Condephaat) e conhecido por ter 
abrigado um colégio de referência no município. O prédio havia sido desocupado em 2009 , devido à diminuição progressiva na oferta de alunos do colégio, que encerrou suas atividades. Nesse ano, o edifício passou a abrigar a Diretoria de Ensino de Santos, a qual dividiu seu espaço com os docentes, discentes e infraestrutura do curso de Engenharia de Petróleo da Poli-USP em Santos a partir de 2012.

Em 2014, porém, o prédio passou a ser ocupado integralmente pela Poli-USP e, em 2017, foi assinado o Decreto n. 62.697/2017 (São Paulo, 2017), formalizando a cessão do imóvel à USP por tempo indeterminado. Atualmente, apenas o curso de Bacharelado em Engenharia de Petróleo é oferecido pela USP na cidade de Santos.

\section{Grade curricular de Geociências da Engenharia de Petróleo da USP}

Este item analisa os aspectos relativos às matérias de Geociências, foco deste estudo. Alguns conceitos-chave, tais como a definição de "crédito" no programa de graduação, serão explanados na seção seguinte do artigo.

Paralelamente às mudanças relativas a tamanho e à localização do curso, houve alterações importantes na sua grade disciplinar. Na fundação do curso, quando estava vigente na Poli-USP o programa da denominada Estrutura Curricular 2 (EC2), as disciplinas da área de Geociências, oferecidas pelo Instituto de Geociências da USP (IGc-USP), iniciavam-se no quinto período ideal (semestre). A EC2 previa o seguinte conjunto de disciplinas no curso de Engenharia de Petróleo, em que 1 UC = 1 Unidade de Crédito:

- Introdução à Mineralogia e Petrologia (60h, 4 UC);

- Geologia Dinâmica e Estratigrafia (60h, 4 UC);

- Introdução à Geoestatística (30h, 2 UC);

- Elementos da Geologia Estrutural (60h, 4 $\mathrm{UC}$;

- Princípios da Geologia Sedimentar (60h, 4 $\mathrm{UC}$;

- Tectônica de Bacias Sedimentares (60h, 4 UC);

- Geologia do Petróleo (60h, 4 UC).

Em 2014, porém, houve mudança na grade curricular dos cursos da Poli-USP, passando a vigorar a Estrutura Curricular 3 (EC3), atualmente em vigor.
$\mathrm{Na}$ estrutura curricular, as disciplinas específicas de Geociências eram oferecidas pelo IGc-USP desde o terceiro período ideal, abrangendo:

- Introdução à Geologia (30h, 2 UC);

- Introdução aos Minerais e Rochas (30h, 2 $\mathrm{UC}$ );

- Elementos da Geologia Estrutural (60h, 4 $\mathrm{UC}$ );

- Princípios de Geologia Sedimentar (60h, 4 UC);

- Geofísica Aplicada à Engenharia de Petróleo (30h, 2 UC);

- Geologia do Petróleo (60h, 4 UC);

- Tectônica de Bacias Sedimentares (30h, 2 $\mathrm{UC}$;

- Introdução à Geoestatística (30h, 2 UC).

É possível observar que na passagem da EC2 para a EC3 houve o aumento no oferecimento de uma disciplina, ao passo que se reduziram quatro UC de aulas, ressalvando-se que a disciplina Geofísica Aplicada à Engenharia de Petróleo, presente na EC3, apesar de pertencer ao campo de Geociências, não consta do elenco de disciplinas do IGc-USP, sendo oferecida pelo PMI.

\section{Programa de graduação em Engenharia de Petróleo da Poli-USP}

O curso de Engenharia de Petróleo foi criado pela Resolução Consolidada n. 3461/1988 em obediência ao Estatuto da USP (Universidade de São Paulo, 1988) e é regido pela Resolução Consolidada n. 3745/1990 do Regimento Geral da USP (Universidade de São Paulo, 1990).

Para esta análise, é importante levar em consideração que as disciplinas oferecidas na USP são dimensionadas de acordo com seu número de créditos (UC). Define-se o "crédito-aula" como equivalente a 15 horas-aula em um semestre. Paralelamente, o "crédito-trabalho" corresponde a cada conjunto de 30 horas de dedicação à disciplina além do período assistido diretamente pelo professor, conforme Artigo n. 65 da Resolução n. 3895/1991 (Universidade de São Paulo, 1991).

Os diplomas normativos da USP também preveem a existência de unidades de ensino com um ou mais departamentos autônomos na Universidade. Assim, na Engenharia de Petróleo, o ofereci- 
mento de disciplinas provém de diversas unidades (Escola Politécnica, Poli; Instituto de Física, IF; Instituto de Matemática e Estatística, IME; Instituto de Química, IQ; e Instituto de Geociências, IGc) e departamentos da USP (a despeito de o curso ser vinculado à Escola Politécnica), conforme Tabela 1.

Adiante, será considerada apenas a Unidade correspondente à oferta da disciplina, pois o IGc-USP oferece uma disciplina interdepartamental para o curso de Engenharia de Petróleo, motivo pelo qual optou-se por simplificar a referência à vinculação de cada disciplina diretamente à Unidade, isentando-se analisar o Departamento de origem.

Assim sendo, a distribuição de oferecimento de disciplinas do curso de Engenharia de Petróleo por unidade é apresentada nas Figuras 2 e 3 a seguir, indicando, respectivamente, a distribuição por número de disciplinas e por número de créditos. A análise da distribuição desconsiderou os créditos-trabalho que eventualmente compusessem as disciplinas.

A divisão se baseou no oferecimento das disciplinas de acordo com sua Unidade de proveniência. Logo, conforme mencionado anteriormente, embora a disciplina Geofísica Aplicada à Engenharia de Petróleo possua um caráter atrelado às Geo-

Tabela 1. Lista de Unidades e Departamentos da USP cujas disciplinas são oferecidas no Curso de Engenharia de Petróleo

\begin{tabular}{|c|c|}
\hline Unidade & Departamentos \\
\hline $\begin{array}{l}\text { Escola } \\
\text { Politécnica } \\
\quad \text { (Poli) }\end{array}$ & $\begin{array}{l}\text { Departamento de Engenharia Minas e de Petróleo (PMI) } \\
\text { Departamento de Engenharia de Produção } \\
\text { Departamento de Engenharia de Construção Civil } \\
\text { Departamento de Engenharia de Transportes } \\
\text { Departamento de Engenharia Química } \\
\text { Departamento de Engenharia Mecânica } \\
\text { Departamento de Engenharia Metalúrgica e de Materiais } \\
\text { Departamento de Engenharia de Energia e Automação Elétricas } \\
\text { Departamento de Engenharia de Estruturas e Geotécnica } \\
\text { Departamento de Engenharia Naval e Oceânica } \\
\text { Departamento de Engenharia Mecatrônica e Sistemas Mecânicos } \\
\text { Interdepartamentais }\end{array}$ \\
\hline $\begin{array}{l}\text { Instituto de } \\
\text { Física (IF) }\end{array}$ & Interdepartamentais \\
\hline $\begin{array}{l}\text { Instituto de } \\
\text { Matemática } \\
\text { e Estatística } \\
\quad \text { (IME) }\end{array}$ & $\begin{array}{l}\text { Departamento de Matemática } \\
\text { Departamento de Matemática Aplicada }\end{array}$ \\
\hline $\begin{array}{l}\text { Instituto de } \\
\text { Química (IQ) }\end{array}$ & Departamento de Química Fundamental \\
\hline $\begin{array}{l}\text { Instituto de } \\
\text { Geociências } \\
\quad(\mathrm{IGc})\end{array}$ & $\begin{array}{l}\text { Departamento de Mineralogia e Geotectônica (GMG) } \\
\text { Departamento de Geologia Sedimentar e Ambiental (GSA) } \\
\text { Interdepartamentais (044) }\end{array}$ \\
\hline
\end{tabular}

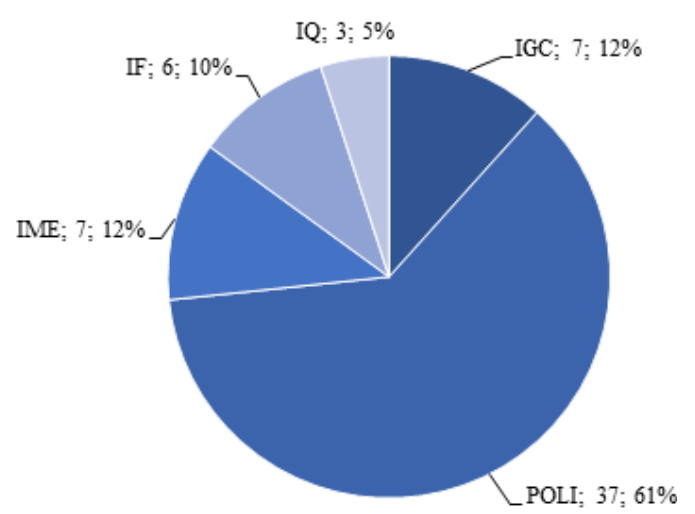

Figura 1. Distribuição do número absoluto de disciplinas por unidade no curso de Engenharia de Petróleo da Poli-USP, estabelecida de acordo com a EC3

ciências, aqui ela está contabilizada como "Poli", por ser oferecida pelo Departamento de Minas e de Petróleo (PMI) da Poli-USP.

\section{Análise Comparativa}

Uma vez apresentado o panorama geral do curso, esta seção se destina a elaborar um quadro comparativo entre as disciplinas de Geociências oferecidas no curso da USP e a "Proposta Curricular para os Cursos de Bacharelado em Engenharia de Petróleo" elaborada pela Society of Petroleum Engineers (SPE, 2014). Na seção anterior observou-se a representatividade das matérias oferecidas pelo IGc-USP no contexto do curso de Bacharelado em Engenharia de Petróleo, o que revelou que a Unidade é a segunda de maior expressão em termos de número absoluto de disciplinas, empatada com o Instituto de Matemática e Estatística (IME) e a terceira unidade de maior expressão quando considerada a quantidade total de créditos. Em ambas as análises a primeira posição é sempre ocupada 


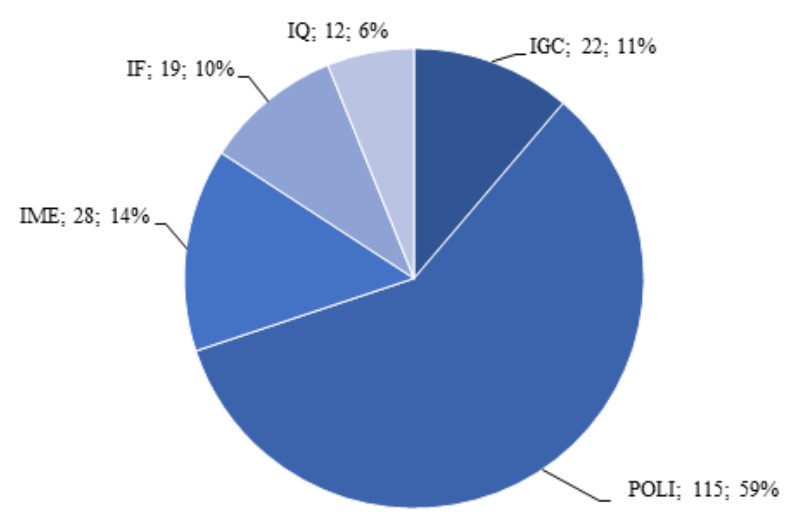

Figura 2. Distribuição de disciplinas por número de créditos por unidade no curso de Engenharia de Petróleo da Poli-USP, estabelecida de acordo com a EC3

Tabela 2. Disciplinas de Geociências no Curso de Engenharia de Petróleo

\begin{tabular}{|c|c|c|c|}
\hline $\begin{array}{c}\text { Semestre } \\
\text { Ideal }\end{array}$ & Código & Disciplina & $\begin{array}{l}\text { Quant. } \\
\text { UC }\end{array}$ \\
\hline $1^{\mathrm{o}}$ & - & - & - \\
\hline $2^{\circ}$ & - & - & - \\
\hline $3^{\circ}$ & 0440208 & $\begin{array}{l}\text { Introdução à } \\
\text { Geologia }\end{array}$ & 2 \\
\hline $4^{\mathrm{o}}$ & GMG0207 & $\begin{array}{c}\text { Introdução aos } \\
\text { Minerais e Ro- } \\
\text { chas }\end{array}$ & 2 \\
\hline \multirow{2}{*}{$5^{\circ}$} & GMG0615 & $\begin{array}{l}\text { Elementos da } \\
\text { Geologia Estru- } \\
\text { tural }\end{array}$ & 4 \\
\hline & GSA0621 & $\begin{array}{l}\text { Princípios da } \\
\text { Geologia Sedi- } \\
\text { mentar }\end{array}$ & 4 \\
\hline $6^{\circ}$ & PMI3319 & $\begin{array}{l}\text { Geofísica Aplica- } \\
\text { da à Engenharia } \\
\text { de Petróleo }\end{array}$ & 2 \\
\hline $7^{\circ}$ & GSA0463 & $\begin{array}{l}\text { Geologia do } \\
\text { Petróleo }\end{array}$ & 4 \\
\hline \multirow[t]{2}{*}{$8^{\circ}$} & GSA0477 & $\begin{array}{c}\text { Tectônica de } \\
\text { Bacias Sedimen- } \\
\text { tares }\end{array}$ & 4 \\
\hline & GSA0602 & $\begin{array}{l}\text { Introdução à } \\
\text { Geoestatística }\end{array}$ & 2 \\
\hline $9^{\circ}$ & - & - & - \\
\hline $10^{\circ}$ & - & - & - \\
\hline
\end{tabular}

pela Poli-USP. A Tabela 2 lista as disciplinas obrigatórias da área atualmente oferecidas pelo IGc para o curso de Engenharia de Petróleo.

É possível observar que as disciplinas relacionadas à área de Geociências encontram-se entre o terceiro e o oitavo semestres ideais do curso.
Destaca-se que os dois últimos semestres ideais, na EC3, comportam o chamado Módulo Vermelho, em que o aluno pode optar por cursar disciplinas de outro Módulo que não o oferecido pelo seu departamento de ingresso na Universidade.

Como forma de verificar os temas abordados pelo curso foi feita a comparação da grade curricular oferecida pela USP com o exemplo proposto pela Society of Petroleum Engineers (SPE, 2014). A SPE é uma associação de profissionais atuantes na área de Engenharia de Petróleo presente em todo o mundo. Em 2014, a SPE/Seção Brasil elaborou a "Proposta Curricular para os Cursos de Bacharelado em Engenharia de Petróleo", documento que, dentre outros tópicos, apresenta os conteúdos programáticos esperados pela organização em um curso de Engenharia de Petróleo. A análise da proposta feita por profissionais da área parece útil ao objetivo deste trabalho, motivo pelo qual passamos a apresentar seu teor.

As disciplinas da área de Geociências sugeridas no documento podem ser visualizadas abaixo:

- Geologia do Petróleo (60h).

- Geofísica aplicada ao E\&P (60h).

- Perfilagem (60h).

Nota-se que a carga horária total sugerida de Geociências (de 180h, ou 12 UC) é consideravelmente menor que a do curso de Engenharia de Petróleo da Poli-USP (de 330h - 22 UC, ou 360h -24 UC, caso seja incluída a disciplina de Geofísica Aplicada à Engenharia de Petróleo).

A ementa da disciplina Geologia do Petróleo prevista pela Society of Petroleum Engineers (SPE, 2014) pode ser observada a seguir:

1. Introdução à Geologia: ciclo geológico;

2. Estrutura da Terra.

3. Geologia Estrutural.

4. Tectônica de Placas.

5. Minerais e Rochas.

6. Rochas sedimentares.

7. Estratigrafia e Sedimentação.

8. Tempo Geológico.

9. Formação de Bacias Sedimentares.

10. Geoquímica do Petróleo.

11. Plays e Prospectos.

12. Sistemas Petrolíferos.

13. Modelagem Geológica.

O conteúdo programático da disciplina Geofísica Aplicada ao E\&P proposta pela Society of 
Petroleum Engineers (SPE, 2014) pode ser acompanhada nos tópicos abaixo:

1. Sequência exploratória de uma bacia sedimentar.

2. Noções de métodos potenciais aplicados à exploração de petróleo.

3. Fundamentos da sísmica de reflexão. Fatores de propagação das ondas elásticas e parâmetros de aquisição de dados.

4. Noções de processamento de dados e imageamento.

5. Obtenção do campo de velocidades. Relações tempo-profundidade;

6. Interpretação de dados geofísicos. A sísmica 3D.

7. Atributos sísmicos, mapas de amplitudes, pseudo impedâncias na caracterização de reservatórios.

8. Fator fluido, geobodies sísmicos, correlação poço-sísmica-produção. A sísmica 4D.

9. Sistemas multicomponentes, microsísmica e monitoramento de fraturas.

Os tópicos abordados pela disciplina de Perfilagem sugerida pela Society of Petroleum Engineers (SPE, 2014) estão dispostos nos itens a seguir:

1. Propriedades físicas das rochas.

2. Ambiente de perfilagem.

3. Equipamentos de perfilagem.

4. Tipos de perfis: potencial espontâneo; raios gama; elétrico convencional; indução; latero-perfis; microrresistividade; sônico; densidade neutrônico.

5. Interpretação quantitativa de perfis: fator de formação; fórmula de Archie; Gradiente geotérmico; Cálculo de resistividade e saturação de água.

6. Interpretação qualitativa de perfis.

7. Outros perfis a poço aberto: ressonância magnética nuclear; espectrometria de raios gama; perfis de mergulho/Dipmeter; perfis de imagens; amostragem lateral.

8. Perfilagem a poço revestido: Production Logging Tool (continuous flowmeter, gradiomanômetro, densidade, hydro-log e temperature); pulse neutronlogging; perfis de testes a cabo.

A seguir serão apresentados os conteúdos programáticos das disciplinas de Geociências previstas no curso da USP, seguidas pelas informações sobre o seu atendimento à proposta da Society of Petroleum Engineers (SPE, 2014).

0440208/Introdução à Geologia:
1. Introdução: origem do Sistema Solar e da Terra (USP possui e SPE não sugere).

2. Estrutura interna da Terra (atendendo tópico "Estrutura da Terra" de Geologia do Petróleo).

3. Composição química e mineralógica da Terra (USP possui e SPE não sugere).

4. Dinâmica interna, tectônica de placas e deriva continental (atendendo tópico "Tectônica de Placas” de Geologia do Petróleo).

5. Ciclo das rochas (atendendo tópico "Introdução à Geologia: ciclo geológico" de Geologia do Petróleo).

6. Ciclo da água em superfície e subterrânea (USP possui e SPE não sugere).

7. Dinâmica externa: intemperismo, erosão, sedimentação e seus produtos (abordagem diferente entre USP e SPE, com mais detalhamento do tema na proposta da USP).

8. Estratigrafia e tempo geológico (atendendo tópico "Estratigrafia e Sedimentação" e "Tempo Geológico" de Geologia do Petróleo).

9. Estruturas geológicas (atendendo tópico "Geologia estrutural” de Geologia do Petróleo).

10. Mapas e perfis geológicos (USP possui e SPE não sugere).

11. Geologia do Brasil (USP possui e SPE não sugere)

12. Recursos naturais (USP possui e SPE não sugere).

GMG0207/Introdução aos Minerais e Rochas: os itens 1 a 6,9 e 10 possuem abordagem diferente entre USP e SPE, com mais detalhamento do tema na proposta da USP, enquanto os itens 7,8 , e de 11 a 13 são abordados pela USP e não são sugeridos pela SPE:

1. Introdução: composição química e mineralógica da crosta da Terra.

2. Minerais: simetria, definição, conceito e classificação.

3. Minerais: propriedades físicas e identificação.

4. Minerais formadores de rochas.

5. Minerais formadores de minérios metálicos e não-metálicos.

6. Os três grandes grupos de rochas.

7. Gênese e colocação de magmas e a formação de rochas ígneas (USP possui e SPE não sugere).

8. Mineralogia, textura e estrutura das rochas ígneas (USP possui e SPE não sugere).

9. Processos supérgenos e formação de rochas sedimentares.

10. Mineralogia, textura e estrutura das rochas sedimentares. 
11. Ambientes metamórficos e formação de rochas metamórficas.

12. Mineralogia, textura e estrutura das rochas metamórficas.

13. Recursos Minerais e exemplos nacionais.

GMG0615/Elementos de Geologia Estrutural (os conteúdos previstos pelos itens 1, 3, 5 e 6 possuem abordagem diferente entre a USP e a SPE, com maior detalhamento do tema na proposta da Universidade; os itens 2, 4, 10, 20 e 21 são abordados pela SPE em disciplinas de Ciências dos Materiais, não sendo abordados pelas Geociências; os demais itens - 7 a 9 e de 11 a 19 - são abordados somente na proposta da USP):

1. Definição e métodos da Geologia Estrutural. Estruturas primárias de rochas ígneas e sedimentares.

2. Comportamento mecânico das rochas.

3. Esforço e deformação.

4. Ruptura de rochas.

5. Fraturas, falhas e juntas.

6. Dobras: descrição e classificação.

7. Foliações e lineações.

8. Mecanismos de dobramento.

9. Zonas de cisalhamento.

10. Análise estrutural.

11. Elementos de Geotectônica.

12. Notação de atitudes de planos e linhas.

13. Mergulho real e aparente.

14. Espessura e profundidade de camadas.

15. Rebatimento de planos.

16. Problema dos três pontos.

17. Intersecção com a topografia.

18. Perfis e mapas geológicos.

19. Projeção estereográfica.

20. Círculo de Mohr.

21. Elipse de deformação.

GSA0621/Princípios de Geologia Sedimentar (os itens 1 a 4 da disciplina atendem aos tópicos "Rochas sedimentares" e "Estratigrafia e Sedimentação" de Geologia do Petróleo da SPE; os itens 5 a 8 são abordados apenas na proposta da Universidade; em 9 e 10 são contemplados os tópicos "Estratigrafia e Sedimentação" de Geologia do Petróleo da SPE; e os itens 11 a 14 atendem ao tópico "Formação de Bacias Sedimentares" de Geologia do Petróleo prevista pela SPE):

1. Sedimentologia: conceitos principais.

2. Rochas sedimentares e sua classificação.
3. Transporte de sedimentos.

4. Estruturas sedimentares e sua classificação.

5. Aula de campo para descrição de rochas e estruturas sedimentares.

6. Conceito de fácies, análise de fácies e modelos faciológicos.

7. Ambientes deposicionais continentais.

8. Ambientes deposicionais transacionais e marinhos.

9. Estratigrafia: conceitos básicos.

10. Nomenclatura e correlações estratigráficas.

11. Métodos de análise de bacias.

12. Gênese, evolução e classificação de bacias sedimentares.

13. Relações entre a tectônica e o preenchimento sedimentar de bacias.

14. Bacias sedimentares brasileiras e sua importância econômica.

PMI3319/Geofísica Aplicada à Engenharia de Petróleo (todos os tópicos atendem parcialmente as ementas das disciplinas de Geofísica Aplicada ao E\&P e Perfilagem da SPE):

1. Fundamentos da Prospecção de Petróleo.

2. Métodos Potenciais (Gravimetria e Magnetometria).

3. Métodos Sísmicos.

4. Fontes e Receptores Sísmicos.

5. Aquisição de Dados Sísmicos.

6. Tipos de Ondas Sísmicas e Velocidades de Propagação.

7. Técnicas de Obtenção de Velocidades.

8. Processamento de Dados Sísmicos.

9. Interpretação de Dados Sísmicos.

10. Sísmica Tridimensional (3D).

11. Sísmica Aplicada à Perfuração e ao Desenvolvimento da Produção.

12. Sísmica 4D.

13. Sísmica de Poço. GSA0463/Geologia do Petróleo:

1. Definição de rocha matriz (atendendo tópico "Sistemas Petrolíferos" de Geologia do Petróleo).

2. Maturação e rocha reservatório (atendendo tópico "Geoquímica do Petróleo" de Geologia do Petróleo).

3. Origem e acumulação da matéria orgânica (atendendo tópico "Sistemas Petrolíferos" de Geologia do Petróleo).

4. Métodos de prospecção (atendendo parcial- 
mente tópicos das disciplinas de Geofísica Aplicada ao E\&P e Perfilagem).

5. Sistemas petrolíferos (atendendo tópico "Sistemas Petrolíferos" de Geologia do Petróleo).

6. Geologia da explotação de reservatórios (atendendo tópico "Plays e Prospectos" de Geologia do Petróleo).

7. Estudo de campo de petróleo com aplicação integrada das informações obtidas com a interpretação sísmica e de perfis (USP possui e SPE não sugere).

GSA0477/Tectônica de Bacias Sedimentares (os itens de 1 a 7 preveem o atendimento ao tópico "Formação de Bacias Sedimentares" da disciplina Geologia do Petróleo da SPE; o item 8 atende parcialmente múltiplos conteúdos previstos na disciplina Geofísica Aplicada ao E\&P; e o item 9 atende o tópico "Plays e Prospectos" previsto pela Geologia do Petróleo da SPE):

1. Tipos de bacias sedimentares em função do regime tectônico: extensional, compressivo e transcorrente.

2. Controle tectônico do embasamento na instalação de bacias sedimentares.

3. Geometria e arquitetura de bacias sedimentares.

4. Desenvolvimento de bacias sedimentares.

5. Principais modelos sedimentares em bacias.

6. Geologia estrutural de bacias sedimentares.

7. Inversão de bacias sedimentares.

8. Expressão sísmica dos diferentes tipos de bacias sedimentares.

9. Hábitat do petróleo nos diferentes tipos de bacias sedimentares.

GSA0602/Introdução à Geoestatística (toda a ementa da disciplina corresponde ao tópico "Modelagem Geológica" previsto pela Geologia do Petróleo da SPE):

1. Revisão de conceitos de estatística.

2. Variáveis regionalizadas.

3. Cálculo de variogramas experimentais, o campo geométrico, modelagem de variogramas experimentais.

4. Técnicas de estimativa geoestatísticas.

5. Dedução das equações de krigagem ordinária a partir da minimização da variância de estimativa.

6. Incertezas associadas à estimativa: variância de krigagem $x$ variância de interpolação.

7. Krigagem pontual $\mathrm{x}$ krigagem de bloco, demonstração da krigagem de bloco, discretização de blocos de cubagem, limites de discretização.

8. Prática da krigagem de bloco, modelo tridimensional de blocos, definição dos limites de mineralização (domínio dos dados).

É notável a diferença, entre as propostas curriculares, na visão das disciplinas nomeadas "Geologia do Petróleo”. Na USP, fundamentalmente, abordam-se os aspectos diretos envolvidos na geração, migração e acumulação de hidrocarbonetos, ao passo que na visão da SPE a disciplina se enquadra como introdução a assuntos básicos de Geologia, com um viés, em seus itens finais, voltada aos sistemas geológicos associados ao petróleo. A disciplina de "Introdução à Geologia" (do IGc-USP) possui perfil parecido com a ementa de "Geologia do Petróleo" (da SPE) com diferenças de abordagem e aprofundamento, mas igualmente de teor introdutório. $\mathrm{Na}$ disciplina da Universidade são contemplados cinco tópicos da ementa apresentada pela SPE (1,2, 4 e 8 em toda a abordagem que será dada ao tema no curso; e 3 que será aprofundado posteriormente por disciplina específica na USP) o que corresponde a cerca de $38 \%$ do programa da disciplina da SPE. Todos os demais tópicos da disciplina proposta pela SPE são abordados posteriormente por disciplinas específicas da Universidade.

As disciplinas "Introdução aos Minerais e Rochas" (tópicos 5 e 6), "Elementos de Geologia Estrutural" (tópico 3), "Princípios de Geologia Sedimentar" (tópicos 6 e 7) e "Introdução à Geoestatística" (tópico 13) do currículo da USP atendem e superam tópicos da "Geologia do Petróleo" sugerida pela SPE e que não foram englobados em "Introdução à Geologia". As disciplinas de "Geologia do Petróleo" e "Tectônica de Bacias Sedimentares" juntas contemplam os tópicos 9 a 12, ou seja, aproximadamente $30 \%$ da ementa de "Geologia do Petróleo" da proposta da SPE.

Os dados demonstram o detalhamento de conteúdo que a Universidade fornece aos aspectos científicos e acadêmicos da formação do Engenheiro de Petróleo em que disciplinas inteiras da USP abordam tópicos de uma disciplina proposta pela SPE.

"Geofísica Aplicada à Engenharia de Petróleo" oferecida pelo PMI atende em sua totalidade à proposta de "Geofísica Aplicada ao E\&P", ainda possuindo conteúdo que é objeto de estudo da disciplina "Perfilagem" da SPE. Apesar de ser um tema introduzido em "Geofísica Aplicada à Engenharia 
de Petróleo" e GSA0463/Geologia do Petróleo, não há, no currículo da USP, uma disciplina obrigatória integralmente dedicada à perfilagem de poços de petróleo, como proposto pela SPE. Atualmente a Universidade disponibiliza a disciplina optativa PMI3928/Perfilagem de Poços, com 4 UC (60h) inteiramente dedicada a essa área do conhecimento.

\section{Discussão e sugestões de mudança}

De acordo com a Resolução n. 509/2008, o Conselho Federal de Engenharia e Agronomia (CONFEA, 2008) dispõe sobre as atividades profissionais do Engenheiro de Exploração e Produção de Petróleo. De acordo com a Resolução, cabe ao Engenheiro de Petróleo o desempenho de atividades para dimensionar, avaliar e explorar jazidas petrolíferas, transporte e industrialização do petróleo e seus derivados. Essas atribuições já estavam previstas na Resolução n. 218/1973 (CONFEA, 1973), porém, apenas com a nova resolução, os Engenheiros de Exploração e Produção de Petróleo deixaram de pertencer à modalidade Química do grupo Engenharia e passaram a integrar a modalidade Geologia e Minas do mesmo grupo. Tanto o Bacharelado em Engenharia de Petróleo da USP, como a proposta da Society of Petroleum Engineers (SPE, 2014) atendem aos requisitos legais para o funcionamento do curso, mas possuem visões diferentes sobre a área.

Ambas as propostas apresentam cursos com aproximadamente 3600 horas dedicadas ao ensino em sala de aula. Desse período, a USP propõe $360 \mathrm{~h}$ dedicadas às Geociências (330h ministradas pelo IGc-USP e 30h ministradas pelo PMI) que representam $10 \%$ da carga horária do curso, enquanto a Society of Petroleum Engineers (SPE, 2014) recomenda $180 \mathrm{~h}$ às Geociências, o que totaliza $\%$ das horas do curso. A USP mantém a tradição de fornecer uma base sólida nos conteúdos teóricos básicos formadores de seu egresso, atendendo e sobrepujando a base fornecida pela disciplina de Geologia do Petróleo da proposta da Society of Petroleum Engineers (SPE, 2014). Por outro lado, a Society of Petroleum Engineers (SPE, 2014) visa dar um embasamento mais forte nas áreas de geofísica e perfilagem de poços, pois são tópicos mais aplicados às demandas do mercado para o profissional da Engenharia de Petróleo.

Com o objetivo de se buscar a excelência e fomentar discussões futuras, recomenda-se o debate a respeito da redução de assuntos acadêmicos e sobrepostos da grade da USP, uma vez que a
Engenharia é um curso de caráter mais técnico e aplicado do que acadêmico e científico, reiterando que ambas as perspectivas são importantes e nenhuma deva ser desconsiderada na montagem de um curso em nível de graduação.

Desta forma seria possível ao curso incluir mais tópicos vinculados às áreas aplicadas e recomendadas pela SPE (2014), mas sem perder a tradição da instituição voltada ao ensino de Geociências e sem gerar aumento no número total de horas do curso. Como forma nortear o debate, sugere-se:

1. A retirada dos tópicos $6,10,11$ e 12 da ementa de 0440208/Introdução à Geologia, além da redução dos tópicos 7, 8 e 9 para somente breves introduções, pois os assuntos serão discutidos novamente em disciplinas posteriores, tendo como objetivo a redução da repetição de ementas entre disciplinas.

2. A simplificação (retirada dos tópicos 1 e 6 - ministrados em 0440208 - Introdução à Geologia; retirada dos tópicos 7, 11 e 13 menos relevantes na formação essencial do Engenheiro de Petróleo; e a retirada do item 9 - ministrado por outras disciplinas que trabalham a dinâmica externa do planeta) da ementa da disciplina GMG0207/Introdução aos Minerais e Rochas e a sua incorporação em 0440208/Introdução à Geologia, reduzindo 2 UC (30h) totais do curso.

3. A retirada dos tópicos 3, 4, 10, 20 e 21 da ementa de GMG0615/Elementos de Geologia Estrutural, pois atualmente são temas ministrados em outras disciplinas obrigatórias do curso não vinculadas às Geociências, além da retirada dos tópicos $8,9,11$ - menos pertinentes na formação Engenheiro de Petróleo, possibilitando a redução das UC da disciplina de 4 (60h) para 2 (30h).

4. A retirada dos tópicos 5, 6, 7, 8 - demasiadamente detalhados para o Engenheiro de Petróleo, além do ajuste dos tópicos 11, 12, 13 e 14, tratados em GSA0477/Tectônica de Bacias Sedimentares, da ementa de GSA0621/ Princípios de Geologia Sedimentar.

5. Suprimir o tópico 8 de GSA0477/Tectônica de Bacias Sedimentares, por ser pauta de outras disciplinas e reduzir, de forma significativa, os demais itens para que a disciplina possa ser integralmente incorporada nos tópicos 11, 12, 13 e 14 de GSA0621/Princípios de Geologia

\begin{tabular}{c|c|c|c|c|c}
\hline (C) Terrae Didat. & Campinas, SP & v.16 & $1-11$ & $\mathrm{e} 020020$ & 2020 \\
\hline
\end{tabular}


Sedimentar, o que reduziria em 4 UC (60h) a carga horária total do curso.

6. Retirada do tópico 7 e simplificação do tópico 4 (para evitar repetição de temas discutidos em PMI3319/Geofísica Aplicada à Engenharia de Petróleo e PMI3928/Perfilagem de Poços) da disciplina GSA0463/Geologia do Petróleo.

7. O programa de GSA0602/Introdução à Geoestatística idealmente seria mais específico à área de modelagem de reservas de hidrocarbonetos, mas como demandaria mais tempo de trabalho para que os alunos recebessem a base teórica do conhecimento necessário, sugere-se o aumento da carga horária da disciplina em 2 UC (30h) para totalizar 4 ou $60 \mathrm{~h}$.

8. A disciplina PMI3928/Perfilagem de Poços, de $4 \mathrm{UC}(60 \mathrm{~h})$, passaria a se tornar obrigatória.

Com essa sugestão o curso reduziria duas disciplinas (GMG0207/Introdução aos Minerais e Rochas e GSA0477/Tectônica de Bacias Sedimentares) para receber a disciplina optativa PMI3928/ Perfilagem de Poços como disciplina obrigatória. Paralelamente, haveria a redução 8 UC $(2$ provenientes de GMG0615/Elementos de Geologia Estrutural; 2 de GMG0207/Introdução aos Minerais e Rochas; e 4 de GSA0477/Tectônica de Bacias Sedimentares) para um aumento de 6 UC provenientes do aumento em 30h de GSA0602/Introdução à Geoestatística e a adição de PMI3928/Perfilagem de Poços como disciplina obrigatória. De forma global, nessa sugestão de reforma curricular o curso reduziria uma disciplina e duas UC, com diminuição de duas disciplinas oferecidas pelo IGc-USP e aumento de uma oferecida pelo PMI da Poli-USP.

\section{Conclusões}

Pela análise de dados e delineação de quadro comparativo entre as propostas curriculares foi possível concluir que a Universidade oferece um leque de disciplinas teórico-acadêmicas muito significativo, ao passo que a Society of Petroleum Engineers possui visão mais pragmática sobre a abordagem das Geociências no curso.

Como forma de promover a discussão sobre a grade curricular de disciplinas de Geociências do Bacharelado em Engenharia de Petróleo da Universidade de São Paulo foi apresentada uma sugestão de reforma, em que há redução do número total de créditos e disciplinas e aproximação do seu conteúdo da perspectiva prática apresentada pela Society of Petroleum Engineers.

\section{Agradecimentos}

O presente trabalho foi realizado com apoio da Coordenação de Aperfeiçoamento de Pessoal de Nível Superior, Brasil (CAPES), Código de Financiamento 001. Os autores agradecem imensamente a contribuição do Centro Acadêmico da Poli-Santos no levantamento de dados empregados no estudo.

\section{Referências}

Brasil. (1997). Lei n. 9.478, de 6 de agosto de 1997. Dispõe sobre a política energética nacional, as atividades relativas ao monopólio do petróleo, institui o Conselho Nacional de Política Energética e a Agência Nacional do Petróleo e dá outras providências. URL: http://www.planalto.gov.br/ccivil_03/leis/ 19478.htm. Acesso 29.09.2019.

Conselho Federal de Engenharia e Agronomia. (1973). Resolução n. 218, de 29 de junho de 1973. (1973). Discrimina atividades das diferentes modalidades profissionais da Engenharia, Arquitetura e Agronomia. URL: https://normativos.confea.org.br/ downloads/0218-73.pdf. Acesso 23.09.2019.

Conselho Federal de Engenharia e Agronomia. (2008). Resolução n. 509, de 26 de setembro de 2008. (2008). Dispõe sobre as atividades profissionais do Engenheiro de Exploração e Produção de Petróleo. URL:: http://normativos.confea.org.br/downloads/0509-08.pdf. Acesso 23.09.2019.

Ortiz Neto, J. B., \& Costa, A. J. D. (2007). A Petrobrás e a exploração de Petróleo Offshore no Brasil: um approach evolucionário. Revista Brasileira de Economia, 61(1), 95-109. doi: 10.1590/S003471402007000100006.

São Paulo. (2017). Decreto n. 62.697, de 12 de julho de 2017. (2017). Autoriza a Fazenda do Estado a permitir o uso, a título precário, gratuito e por prazo indeterminado, em favor da Universidade de São Paulo - USP, do imóvel que especifica no Município de Santos. URL: https://www.al.sp. gov.br/repositorio/legislacao/decreto/2017/decreto-62697-12.07.2017.html. Acesso 29.09.2019.

Society of Petroleum Engineers (SPE). (2014). Proposta Curricular para os Cursos de Bacharelado em Engenharia de Petróleo. Fórum Permanente de Estudos Ligados à Educação em Engenharia de Petróleo. URL: http:// www.spebrasil.org/wp-content/uploads/2015/12/ Proposta-Curricular-Para-os-Cursos-de-Bacharelado-em-Engenharia-de-Petroleo-SPE-SecaoBrasil.pdf. Acesso 04.09.2019.

Universidade de São Paulo. (1988). Resolução Consolidada 
n. 3461, de 7 de outubro de 1988. (1988). Baixa o Estatuto da Universidade de São Paulo. URL: http:// www.leginf.usp.br/?resolucao $=$ consolidada-resolucao-no-3461-de-7-de-outubro-de-1988. Acesso 30.09.2019.

Universidade de São Paulo. (1990). Resolução Consolidada n. 3745, de 19 de outubro de 1990. (1990). Baixa o Regimento Geral da Universidade de São Paulo. URL: http://www.leginf.usp.br/?resolucao = consolidadaresolucao-no-3745-de-19-de-outubro-de-1990. Acesso 30.09.2019.

Universidade de São Paulo. (1991). Resolução n. 3895, de 29 de novembro de 1991. (1991). Dispõe sobre o valor do "crédito trabalho" nos cursos de graduação. URL: http://www.leginf.usp.br/?resolucao= resolucao-no3895-de-29-de-novembrode-1991. Acesso 30.09.2019. 